\title{
A Longitudinal Analysis of Gambling Predictors among Adolescents
}

\author{
Álvaro Botella-Guijarro ${ }^{1,2}$ (D) Daniel Lloret-Irles ${ }^{2, *}$, José Vicente Segura-Heras ${ }^{3} \mathbb{1}$, \\ Víctor Cabrera-Perona ${ }^{2}$ (D) and Juan Antonio Moriano ${ }^{1}$ \\ 1 Department of Social and Organizational Psychology, Universidad Nacional de Educación a \\ Distancia (UNED), 28015 Madrid, Spain; alvarbot@cop.es (Á.B.-G.); jamoriano@psi.uned.es (J.A.M.) \\ 2 Health Psychology Department Universidad Miguel Hernández de Elche, 03202 Elche, Spain; \\ vitorperona@gmail.com \\ 3 Department of Statistics, Mathematics and Informatics Universidad Miguel Hernández de Elche, \\ 03202 Elche, Spain; jvsh@umh.es \\ * Correspondence: daniel.lloret@umh.es; Tel.: +34-965-919-406
}

Received: 21 October 2020; Accepted: 8 December 2020; Published: 11 December 2020

\begin{abstract}
Although gambling is forbidden for minors, the prevalence of gambling among adolescents is increasing. In order to improve preventive interventions, more evidence on predictors of gambling onset is needed. A longitudinal study was proposed to (1) establish the prevalence of gambling; (2) identify factors associated with gambling behavior the following year; and (3) adjust a model to predict gambling behavior. A cohort of 1074 students (13-18 years old) was followed for 12 months. The prevalence of gambling reached $42.0 \%$ in the second measure. Boys gambled 2.7 times more than girls, and the highest percentages of gambling onset showed up between 13 and 14 years old. Gambling onset and maintenance was associated with gender, age, sensation-seeking, risk perception, self-efficacy for not gambling, parents' attitude towards gambling, group pressure (friends), subjective norm, exposure to advertising, accessibility, normative perception, gambling in $T_{1}$ and parents gambling behavior. Gender, gambling in $\mathrm{T}_{1}$ and risk perception were significant in all three logistic adjusted regression models, with the fourth variable being sensation seeking, peer pressure (friends) and accessibility, respectively. It is suggested that universal prevention should be aimed preferably at children under 15 years old and to alert regulators and public administrations to the directly proportional relationship between accessibility and gambling onset.
\end{abstract}

Keywords: gambling; adolescence; generalized linear model (GLM); risk factor

\section{Introduction}

Gambling is an international phenomenon that involves adolescents and the young population. In Europe, 12-70\% of teenagers report having gambled in the last 12 months, with the proportion of excessive gamblers being $15 \%$ and problematic gamblers, 5.0\% [1-3]. In Spain, the prevalence of gambling in the last year among students aged from 14 to 18 varies from 22 to $62 \%$ [4-6]. The latest ESPAD Report [2] outlines a European average of $22 \%$ of adolescents who have gambled in the "last 12 month". The previous ESPAD survey [7] reports that $14 \%$ of European adolescents gambled "at least once in their life". Although the measure has changed between the two waves, and the interpretation should be taken with caution, the prevalence of gambling has increased among the European population aged 15-16 years. On the other hand, the biennial survey among adolescents carried out by the Spanish Observatory of Drugs and Addictions (OEDA) reports an increase in the prevalence of online gambling from $6.4 \%$ in 2016 to $10.3 \%$ in 2018 [8]. This high prevalence is due in part to online gambling, which has extended availability and increased capacity to intrude into many 
online activities and intimate spaces, facilitating a sense of security, immunity and anonymity $[9,10]$. In Spain, online gambling represents more than $20 \%$ of total gambling, with $25.32 \%$ of users between 18 and 25 years old [11,12]. In addition, online players have a higher rate of problematic gambling than offline players [13] and bet on more modes of play [14,15]. In adolescence, critical thinking and other cognitive skills are still developing, which makes adolescents more prone to gambling [4,16-20]. In this sense, the prevalence of risk and/or problem gambling among adolescents is higher than in adults $[4,17-21]$.

Early gambling increases the probability of developing addictive behavior as an adult [22-24]. Regarding adolescents at-risk gambling, a recent European review [21] shows the highest prevalence rates in Spain, possibly due to recent online gambling legalization and high accessibility to gambling halls. Thus, in Spain, the proportion of nonproblematic gamblers who began gambling before the age of 18 is $13.4 \%$ and increases to $44.8 \%$ among problematic and pathological gamblers [12]. Since the appearance of online gambling, the proportion of young people who require treatment for gambling addiction has increased, with the main demand being for online gambling [25].

Therefore, carrying out preventive initiatives that target adolescents is of special importance. A conceptual framework for the development of preventive initiatives based on evidence, with broad support in the scientific literature, is Dickson's model [26,27]. The model suggests that risk and protective factors are specific and common for different risk behaviors. Some of the most common factors are biological (e.g., family history of problem behavior), social environment (e.g., low socioeconomic status), perceived social-environment (e.g., role models for problem behavior), personality (e.g., low self-esteem) and behavior (e.g., other problem behaviors) [28].

The specific risk factors for gambling incorporated into the model are lack of coping skills, cognitive bias and fallacies about gambling, accessibility, permissiveness with underage gambling, and having friends who also gamble $[29,30]$.

St-Pierre and Derevensky [31] classify the programs aimed at adolescents into psychoeducational prevention programs and psychoeducational prevention programs with skills training. The latter include components to reduce gambling misinformation, probability, cognitive bias about gambling, and risk perception. For the skills training, a wide variety of topics are included, such as self-esteem, social and coping skills, decision-making, problem solving and skills to refuse to gamble [16,28,32].

Other authors consider that gambling among adolescents is also predicted by non-reflective processes such as behavior-driven by affordances [33], normative perception and judgment about gambling behavior when it is approved by people who are considered important $[34,35]$ to the individual. Taking the above into account, it is proposed to find the risk factors that predict gambling behavior, among those which make up the components of adolescent gambling prevention programs.

These factors can be classified according to personal, relational, sociodemographic or environmental characteristics. Among the personal features, there is grounded evidence regarding impulsiveness and sensation seeking. Adolescence is a period in which impulse control plays an important role in behavior understanding. Impulsiveness is considered a multidimensional construct, with at least three potentially independent types: Acting without planning or thinking about the consequences, also called lack of premeditation; Showing impatience when deciding between an immediate reward and a bigger but delayed reward; and sensation-seeking being, the tendency to seek new, exciting, or rewarding experiences [36,37]. A wealth of research exists on the relationship between gambling and impulsiveness in cross-sectional [38-41] and longitudinal studies [22,42,43], as well as the meta-analysis [19]. Other personal risk factors are the low perception of the risks of gambling [43,44], adolescents understand that gambling can carry risks but do not consider themselves as a possible victim [30]; and low self-efficacy for refusing gambling opportunities [43-46]. Different theoretical models, such as COM-B [47], or the theory of planned behavior [48], assume self-efficacy as a crucial factor for behavior explanation. Regarding family characteristics, there is solid evidence that relates that parent's attitudes and behavior towards gambling are conducive to adolescents' gambling behaviors [49,50]. Likewise, parental supervision is a common variable for many risk behaviors [34]. 
Among the interpersonal or relational factors, two factors stand out: the number of friends who gamble (peer pressure), and the opinion they have about gambling and how important it is for the adolescent (subjective norm). Both factors reinforce the adolescent's identity in her/his peer group and predispose him/her to imitate the group behaviors [29,30,51], reducing the skills to refuse risk behaviors [52]. Another psychosocial factor is normative perception, understood as the belief that gambling behavior is normal in adolescence [31,53].

From an environmental perspective, exposure to gambling advertising [54-57] and accessibility to gambling [5,58-61] are risk factors that increase the probability of gambling in adolescents. Among sociodemographic factors, age and male gender correlate with gambling frequency in the vast majority of studies $[4,5,11,21]$.

Finally, adolescents keep a high fidelity to gambling once they have a first experience $[22,43,55,62]$. In this sense, the performance of gambling-like behaviors, either with simulated gambling [63,64] or with video games with similar features to online gambling [65], are related to an earlier gambling onset.

Framed into a socioecological model [66], the present study aims to fill the existing gaps in the literature. Although previous longitudinal studies have identified several risk and protective factors, the age ranges are too wide and heterogeneous $[67,68]$, and the goals were to predict problem gambling in adulthood $[68,69]$. To our knowledge, no study has examined the age range that encompasses the entire adolescence (13-17 years), and no longitudinal studies were conducted in the Spanish population. Since gambling in Spain was regularized in 2011, media pressure has grown enormously, especially in timeframe and channels for children and young people. Unlike previous studies, and in coherence with the components of prevention programs [70,71], this work includes media pressure and advertising among the predictive variables.

Research is needed to identify and delimit factors associated with the problem of gambling, especially those related to social relationships and environmental $[19,72]$

Cross-sectional studies are the most widely used design method; however, the results of this method only show the association between risk factors and consumption, without the ability to analyze causality. Longitudinal studies are the most powerful design for making causal inferences [73].

The objectives of the present study are (1) to explore the prevalence of gambling from a longitudinal perspective (2) to identify which psychosocial factors predict the initiation and maintenance of gambling behavior in adolescents; and (3) to create a mathematical model to predict gambling behavior. We expect to find prevalences within the range of the mentioned research (Hypothesis 1); the factors studied will all be associated with the initiation or maintenance of gambling behavior in the second year (Hypothesis 2). As for the predictive model, gender and gambling behavior in the first year will be predictive variables of gambling in the second year (Hypothesis 3). Accessibility to gambling and the fact that friends gamble may be other predictors that make up the predictive algorithm (Hypothesis 4).

\section{Materials and Methods}

\subsection{Participants}

The sample was recruited in two consecutive years in 15 high schools in the region of Alicante (Spain). At the time of the first measurement $\left(T_{1}\right)$, the sample was composed of 2716 students of the third and fourth year of compulsory secondary education (ESO) and 1st year of the baccalaureate (BAC); with an average age of 15.12 (SD = 1.03; range 13-17) and $49.9 \%$ girls. At the time of the second measurement $\left(\mathrm{T}_{2}\right), 2430$ students from the fourth year of ESO, first of the BAC and second of the BAC, participated, with an average age of 16.07 ( $\mathrm{SD}=0.99$; range $14-19), 54.8 \%$ girls.

The paired sample $\mathrm{T}_{1}-\mathrm{T}_{2}$ is formed by 1074 students from the 4 th year of ESO, and the 1 st and second years of BAC, with $55.12 \%$ girls and an average age of $15.06(\mathrm{SD}=1.01$; range 13-18). $60.46 \%$ of participants from $\mathrm{T}_{1}$ and $55.85 \%$ of participants from $\mathrm{T}_{2}$. The experimental loss was due to (1) the impossibility of measuring students who changed schools or municipalities after completing 
compulsory education in the next academic year; (2) failure to obtain parental permission and/or absenteeism; (3) errors or falsification in the coding of anonymous keys.

\subsection{Procedure}

After authorization was obtained from the competent authority in education, the study was approved by the Ethics Committee of the Miguel Hernández University (DPS.DLI.01.17). The educational centers were randomly selected, with a ratio of two centers per town, and within each center, all classes from each educational were selected. The valid cases, excluding questionnaires with random pattern or desirability, was up to $85 \%$. Informed consent was obtained from the parents and guardians of the participants. The adolescents participated voluntarily after having been informed of the purpose of the study. No exclusion criteria were used. The duration of the sessions was $25-30 \mathrm{~min}$, and the test was completed collectively, under the supervision of the research team.

\subsection{Measures}

Gambling frequency was informed with a survey adapted from the European school survey project on alcohol and other drugs (ESPAD) questionnaire. The number of times gambled (a) during the lifetime, (b) in the last 12 months, (c) in the last 30 days; in eight gambling modes: online sports betting, sports betting in gambling parlors and/or bars, slot machines in gambling parlors and/or bars, online poker, poker with friends, online casino games, roulette in gambling parlors, and noncommercial betting among peers was measured. Higher scores indicate a higher frequency. The frequency was categorized into four categories: (I) Does not gamble (never played betting games); (II) Occasional frequency (having gambled in online sports betting or slot machines less than five times in a lifetime and less than four times in the last 12 months and never played poker or roulette); (III) Moderate frequency (having gambled at poker or roulette less than three times in a lifetime, sports betting or slot machines less than three times in the last 30 days, less than seven in the last year, and less than eight over a lifetime); and (IV) High frequency (having gambled in the last 30 days more than three times at sports betting or slot machines, or more than twice at online poker or roulette rooms).

For the statistical modeling, we grouped the no gambling and occasional frequency categories into one category (infrequent gambling), while moderate frequency and high frequency were grouped into the frequent gambling category.

Problematic gambling was measured with the SOGS-RA (South Oaks gambling scale-RA) [74,75]. 12 dichotomous items and one Likert-type item. Reliability, Cronbach's $\alpha=0.72$. SOGS-RA scores provide three categories: (1) non-gambler or nonproblematic gambler with scores $\leq 1$; (2) at-risk gambler, with scores between 2 and 3; and (3) problematic gambler, with scores $\geq 4$.

Impulsivity was measured with Plutchik's impulsivity scale [76,77], consisting of 15 phrases scored on a scale of four alternatives $(0=$ never, $3=$ almost always $)$. Internal consistency: Cronbach's $\alpha=0.68$.

Sensation-seeking was assessed with the brief sensation-seeking scale (BSSS-8) [78-80]. An 8-item questionnaire, which evaluates four factors: thrill-seeking and adventure, experience-seeking, disinhibition, and susceptibility to boredom. Internal consistency: Cronbach's $\alpha=0.76$.

Self-efficacy not to gamble (ad-hoc scale) was measured with an 8-item questionnaire that evaluates the ability to not gamble in situations where gambling is encouraged. A 5-option Likert scale was used ( $0=$ non capable, $4=$ totally capable). The internal consistency value of Cronbach's $\alpha$ was 0.85 .

Peer pressure was scored with an ad-hoc scale that evaluated the perception of gambling among friends with 8 independent items with the same wording, one for each gamble, in the form, "How many friends do you think that gamble ... ?".

Subjective norm was the result of the combination of the perceived opinion about gambling from parents, friends, classmates, teachers, and romantic partners, and the importance that this opinion has for the respondent. We used an ad-hoc questionnaire consisting of 5 items per scale (Likert scale), which were multiplied to obtain the score for this variable (range 0 to 16). 
Parents' attitude towards gambling ( 8 items), norm perception (4 items), accessibility ( 6 items) and risk perception ( 8 items) were measured with the EDGAR-A battery (early detection gambling addiction risk-adolescents) [81]. A 5-point Likert scale was used. Internal consistency: Cronbach $\alpha=0.86$ for parental attitude to gambling, 0.80 for norm perception, 0.74 for accessibility, and 0.79 for risk perception.

Parenting gambling behavior was scored using a five-item, ad-hoc questionnaire that assessed whether parents engage in any form of gambling: sports betting, slot machines, poker, casinos, or bingo.

Media pressure was scored with a 12-item Likert scale, which evaluated the perception of exposure to advertising regarding sports betting and casino and online poker from different media outlets such as television, Internet, radio, magazines, outdoor advertising and the presence of gambling parlors in public. The response ranged from 0 (never) to 4 (very often).

\subsection{Statistical Analysis}

A cross-sectional descriptive analysis of variables related to gambling behavior at time points $\mathrm{T}_{1}$ and $\mathrm{T}_{2}$ (frequency of gambling, intention to gamble, and problem gambling) by gender and age was conducted.

For predictive analysis, continuous variables were represented by their means and standard deviations, while categorical variables were expressed as frequency and percentages. A $t$-test for independent samples was carried out to evaluate the statistical significance of the continuous variables, and a chi-squared test for the categorical variables. For the adjustment of the multivariate logistic regression model, $2 / 3(n=721)$ of the sample (derived or origin sample) was randomly selected. The remaining third $(n=353)$ was used to validate the model (validation sample). This model was used to estimate the probability of "gambling behavior in $\mathrm{T}_{2}$ ". For its construction, all the variables that presented a $p<0.10$ value in the univariate analysis were considered. Odds ratios and their $95 \%$ confidence intervals were calculated from the coefficients of the final model. To measure the goodness of fit of the model, the Hosmer and Lemeshow (HL) test was performed. Nagelkerke's R2 value was used to estimate the variability ratio. We tested the assumption of multicollinearity through the variance inflation factor (VIF).

Discrimination and prediction accuracy were assessed by means of the area under the curve (AUC) by calculating the receiver operating characteristic curve (ROC). AUC ranges below 0.5 are considered non-informative and close to 1.0 as perfect prediction models. A $p<0.05$ value was considered statistically significant. Statistical analysis was performed with R software [82].

We used the forward stepwise regression to select step-by-step, the most important variable. The first three variables, in order of importance, were: Gambling behavior in $\mathrm{T}_{1}$, gender and risk perception in $\mathrm{T}_{1}$. The $\mathrm{R} 2$ Nagelkerke values increased from 0.213 to 0.285 and 0.302 , respectively. When we selected the fourth variable: sensation seeking, peer pressure and availability were interchangeable. When the three of them were included, none of them were significant. However, when they were added separately, all three were significant. Therefore, once gender, gambling in $\mathrm{T}_{1}$ and risk perception were fixed, we built three logistic regression models. One for each of the other three considered variables. Akaike's information criterion would recommend that we stick with model C; however, the results are similar in all three; therefore, we considered it relevant to present them all.

\section{Results}

Regarding the frequency of gambling, $28.50 \%$ report having played at some time in their lives in $\mathrm{T}_{1}$, with one year later $\left(\mathrm{T}_{2}\right)$ it being $42.0 \%$. Table 1 shows the percentages, according to the different frequencies of gambling contemplated, by gender and the total of the sample, for $T_{1}$ and $\mathrm{T}_{2}$. The differences in frequency between boys and girls are statistically significant, both in $\mathrm{T}_{1}\left(\chi^{2}(3, n=2716)=286.92 ; p<0.001\right)$, and in $\mathrm{T}_{2}\left(\chi^{2}(3, n=2430)=400.91 ; p<0.001\right)$. Analyzing the adjusted standardized residuals from the contingency table of the frequency and gender variables, 
in $\mathrm{T}_{1}$, all the residuals are greater than $1.96(p<0.05)$. In $\mathrm{T}_{2}$, only those in the frequency categories "do not gamble" and "high" are greater than $1.96(p<0.05)$.

Table 1. Gambling frequencies by gender and totals for $T_{1} \& T_{2}$.

\begin{tabular}{ccccccc}
\hline & \multicolumn{3}{c}{$\mathbf{T}_{\mathbf{1}}(\boldsymbol{n = 2 7 1 6 )}$} & \multicolumn{3}{c}{$\mathbf{T}_{\mathbf{2}}(\boldsymbol{n}=\mathbf{2 4 3 0})$} \\
\cline { 2 - 7 } & Male & Female & Total & Male & Female & Total \\
\hline Never & 53.6 & 81.4 & 71.5 & 39.27 & 73.3 & 57.9 \\
Low & 7.5 & 5.5 & 10.7 & 4.27 & 5.9 & 5.2 \\
Average & 14.8 & 8.6 & 4.5 & 9.82 & 9.6 & 9.7 \\
High & 24.1 & 4.5 & 13.3 & 46.6 & 11.2 & 27.2 \\
\hline
\end{tabular}

Figures 1 and 2 show the graphs for the frequency of gambling among the people who gamble within the past 12 months, in relation to age at $T_{1}$ and $T_{2}$.

Low $\square$ Average $\square$ High

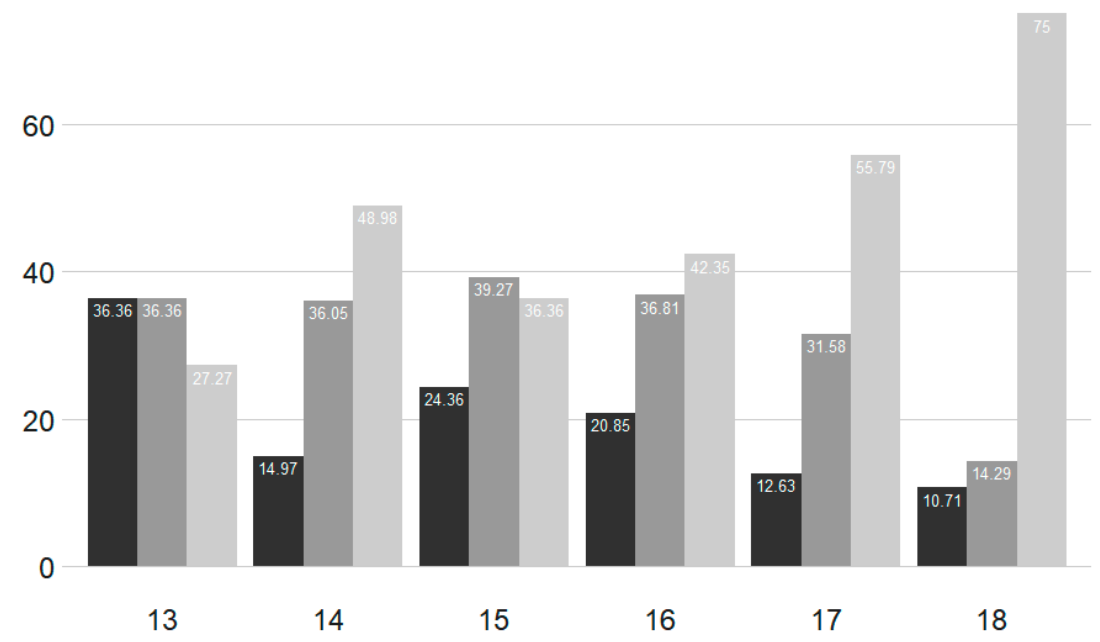

Figure 1. Gambling frequencies by age $(\%)$ for $T_{1}(n=774$ individuals who gambled within the past 12 months).

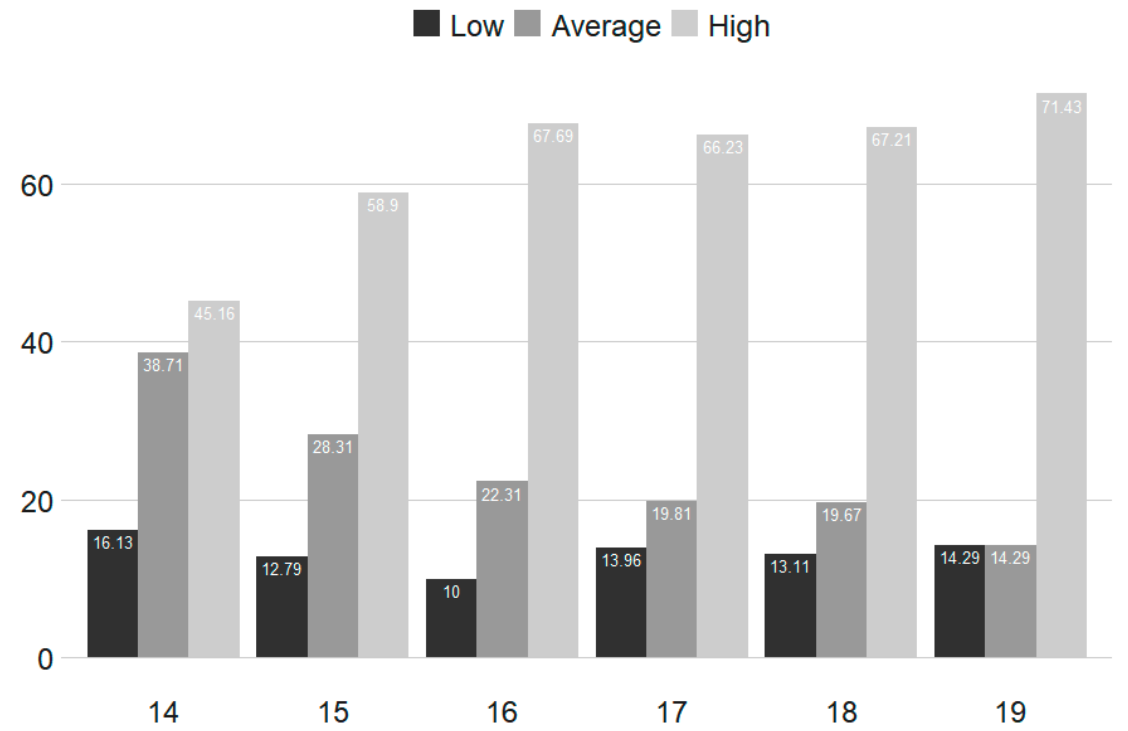

Figure 2. Gambling frequencies by age (\%) for $\mathrm{T}_{2}(n=1023$ individuals who gambled within the past 12 months). 
Analysis of the results of problem gambling (SOGS-R) in $\mathrm{T}_{2}$ showed 70 cases $(2.87 \%)$ of problem gamblers and 116 cases $(4.76 \%)$ for at-risk gamblers. The distribution by gender and age of at-risk and problem gamblers is shown in Figure 3.
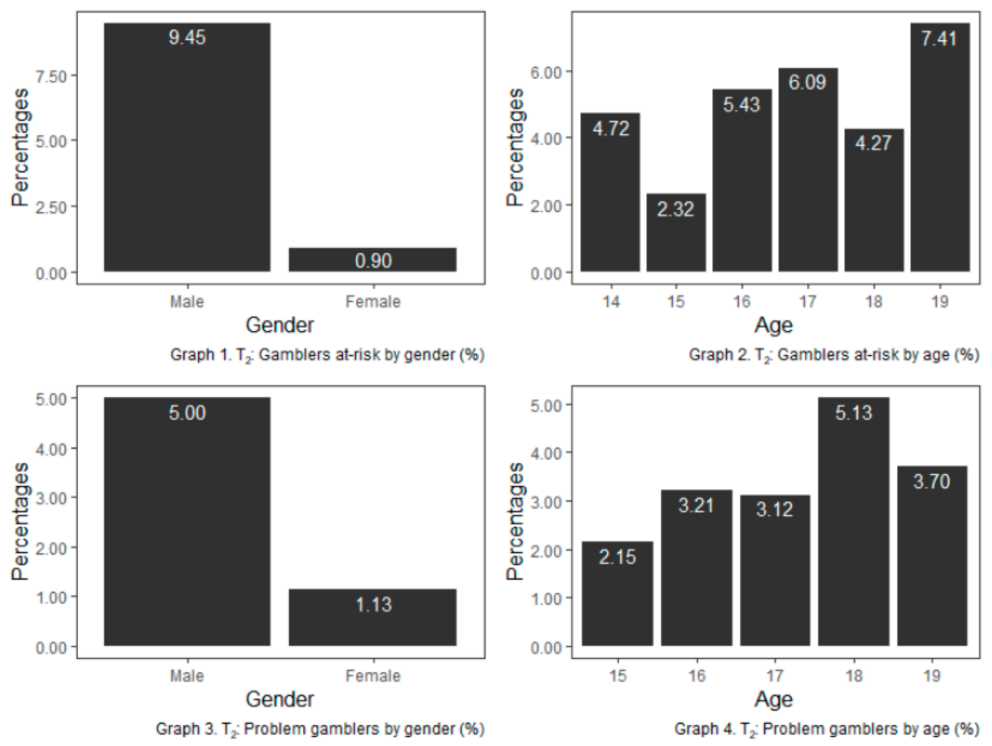

Figure 3. At-risk and problem gamblers by age and gender (\%) for $\mathrm{T}_{2}$. The percentage refers to both the percentage of total males or females who are classified as a risk $(n=116)$ or problem gambler $(n=70)$ and the percentage of total youths of each age who are classified as a risk or problem gambler.

On the other hand, with the samples in $T_{1}$ and $T_{2}$ paired, the results show that the highest number of initiations to gamble occurs between 13 and 14 years old.

For the predictive analyses, Tables 2 and 3 show the results of the univariate analyses of the predictor variables in $\mathrm{T}_{1}$ with respect to gambling behavior in $\mathrm{T}_{2}$. Except for "impulsivity" and "subjective norm", all the analyzed factors register higher scores in $\mathrm{T}_{1}$ in the adolescents who gamble in comparison to those who do not gamble. The factor "self-efficacy to not gamble" reverses this result since, unlike the others, higher scores indicate a lower risk of gambling.

Table 2. Average scores for infrequent gamblers and gamblers and $p$-value for the $t$-test of differences between groups.

\begin{tabular}{|c|c|c|c|c|c|c|}
\hline & \multicolumn{4}{|c|}{ Gambling Behavior for $T_{2}$} & \multirow{3}{*}{$95 \% \mathrm{CI}$} & \multirow{3}{*}{$p$-Value } \\
\hline & \multicolumn{2}{|c|}{ Infrequent Gambling } & \multicolumn{2}{|c|}{ Frequent Gambling } & & \\
\hline & $n$ & Mean \pm SD & $n$ & Mean \pm SD & & \\
\hline Age & 707 & $14.99 \pm 1.00$ & 364 & $15.18 \pm 1.02$ & $(-0.32,-0.06)$ & 0.003 \\
\hline Sensation-seeking & 708 & $3.29 \pm 0.77$ & 366 & $3.42 \pm 0.75$ & $(-0.23,-0.04)$ & 0.007 \\
\hline impulsivity & 708 & $2.35 \pm 0.36$ & 366 & $2.39 \pm 0.38$ & $(-0.08,0.01)$ & 0.124 \\
\hline Risk perception & 696 & $1.44 \pm 0.64$ & 362 & $1.73 \pm 0.75$ & $(-0.38,-0.20)$ & $<0.001$ \\
\hline Self-efficacy not to gamble & 693 & $3.49 \pm 0.66$ & 354 & $3.29 \pm 0.79$ & $(0.11,0.30)$ & $<0.001$ \\
\hline Parents attitude & 677 & $0.87 \pm 0.71$ & 348 & $1.05 \pm 0.87$ & $(-0.29,-0.08)$ & 0.001 \\
\hline Group pressure (friends) & 678 & $0.44 \pm 0.52$ & 352 & $0.75 \pm 0.68$ & $(-0.39,-0.23)$ & $<0.001$ \\
\hline Subjective norm: parents & 702 & $4.83 \pm 2.82$ & 359 & $5.61 \pm 3.46$ & $(-1.19,-0.36)$ & $<0.001$ \\
\hline Subjective norm: friends & 701 & $7.20 \pm 3.57$ & 358 & $7.89 \pm 4.16$ & $(-1.20,-0.19)$ & 0.007 \\
\hline Subjective norm: peers & 699 & $5.17 \pm 3.10$ & 358 & $5.25 \pm 3.42$ & $(-0.50,0.35)$ & 0.721 \\
\hline Subjective norm: teachers & 700 & $4.03 \pm 2.60$ & 359 & $3.68 \pm 2.74$ & $(0.01,0.69)$ & 0.041 \\
\hline Subjective norm: partner & 686 & $6.04 \pm 3.45$ & 355 & $6.95 \pm 4.00$ & $(-1.4,-0.42)$ & $<0.001$ \\
\hline Exposure to publicity & 706 & $24.18 \pm 6.36$ & 366 & $26.3 \pm 6.72$ & $(-2.94,-1.30)$ & $<0.001$ \\
\hline Accessibility & 659 & $2.41 \pm 0.68$ & 345 & $2.63 \pm 0.66$ & $(-0.31,-0.13)$ & $<0.001$ \\
\hline Normative perception & 696 & $2.00 \pm 0.75$ & 353 & $2.31 \pm 0.88$ & $(-0.41,-0.20)$ & $<0.001$ \\
\hline
\end{tabular}

$\mathrm{SD}=$ standard deviation. $\mathrm{CI}=$ Confidence Interval 
Table 3. Distribution for gambling behavior at $\mathrm{T}_{2}$ compared to $\mathrm{T}_{1}$ and $p$-value according to chi-squared.

\begin{tabular}{cccc}
\hline & \multicolumn{2}{c}{ Gambling Behavior at $\mathbf{T}_{\mathbf{2}}$} & \\
\cline { 2 - 3 } & $\begin{array}{c}\text { Infrequent Gambling } \\
\boldsymbol{n} \mathbf{( \% )}\end{array}$ & $\begin{array}{c}\text { Frequent Gambling } \\
\boldsymbol{n} \mathbf{( \% )}\end{array}$ & \\
\hline Gambling behavior at $\mathrm{T}_{1}$ & & & $<0.001$ \\
No gamble & $649(76.4)$ & $201(23.6)$ & \\
Yes gambles & $59(26.3)$ & $165(73.7)$ & $<0.001$ \\
Gender & & & \\
Male & $234(48.5)$ & $248(51.5)$ & 0.002 \\
Female & $474(80.1)$ & $118(19.4)$ & \\
\hline Gambling behavior of parents & & & \\
Do not gamble & $574(68.3)$ & $266(31.7)$ & $100(42.7)$ \\
At least one gambles & $134(57.3)$ &
\end{tabular}

The three final models adjusted with the derivation sample identified four significant independent variables that pointed to gambling behavior in $\mathrm{T}_{2}$ : gambling behavior in $\mathrm{T}_{1}$, gender, risk perception, in all models, and sensation seeking, peer pressure or accessibility, depending on the model (Table 4 and Figures 4-6). The $p$-value associated with the HL goodness-of-fit test was greater than 0.05, and Nagelkerke's R2 value was greater than 0.30. Model C showed the lowest Akaike information criterion (AIC).

Table 4. Adjusted multivariate logistic regression models.

\begin{tabular}{|c|c|c|c|c|c|c|c|c|}
\hline Variable & Beta & $p$-Value & OR & $95 \%$ CI & VIF & AIC & $\begin{array}{c}\text { R2 } \\
\text { Nagelkerke }\end{array}$ & HL \\
\hline Model A & & & & & & 725.36 & 0.308 & 0.933 \\
\hline Constant & -2.013 & & & & & & & \\
\hline Gambling behavior at $T_{1}$ & 1.680 & $<0.001$ & 5.364 & $3.48-8.34$ & 1.03 & & & \\
\hline Gender & -1.207 & $<0.001$ & 0.299 & $0.21-0.43$ & 1.04 & & & \\
\hline Risk perception & 0.412 & 0.003 & 1.509 & $1.15-1.99$ & 1.02 & & & \\
\hline Sensation-seeking & 0.252 & 0.046 & 1.287 & $1.01-1.65$ & 1.03 & & & \\
\hline Model B & & & & & & 693.14 & 0.302 & 0.776 \\
\hline Constant & -1.374 & & & & & & & \\
\hline Gambling behavior at $\mathrm{T}_{1}$ & 1.525 & $<0.001$ & 4.596 & $2.92-7.31$ & 1.10 & & & \\
\hline Gender & -1.154 & $<0.001$ & 0.315 & $0.22-0.46$ & 1.02 & & & \\
\hline Risk perception & 0.401 & 0.004 & 1.493 & $1.14-1.97$ & 1.01 & & & \\
\hline Peer pressure (friends) & 0.412 & 0.018 & 1.510 & $1.07-2.13$ & 1.08 & & & \\
\hline Model C & & & & & & 684.45 & 0.302 & 0.669 \\
\hline Constant & -1.927 & & & & & & & \\
\hline Gambling behavior at $\mathrm{T}_{1}$ & 1.615 & $<0.001$ & 5.027 & $3.23-7.90$ & 1.04 & & & \\
\hline Gender & -1.150 & $<0.001$ & 0.317 & $0.22-0.46$ & 1.02 & & & \\
\hline Risk perception & 0.422 & 0.004 & 1.524 & $1.15-2.03$ & 1.02 & & & \\
\hline Accessibility & 0.294 & 0.040 & 1.341 & $1.02-1.78$ & 1.02 & & & \\
\hline
\end{tabular}

OR: odds ratio; $\mathrm{CI}=$ confidence interval; VIF: variance inflation factor. $\mathrm{HL}=$ Hosmer and Lemeshow test. AIC: Akaike Information Criterion. 


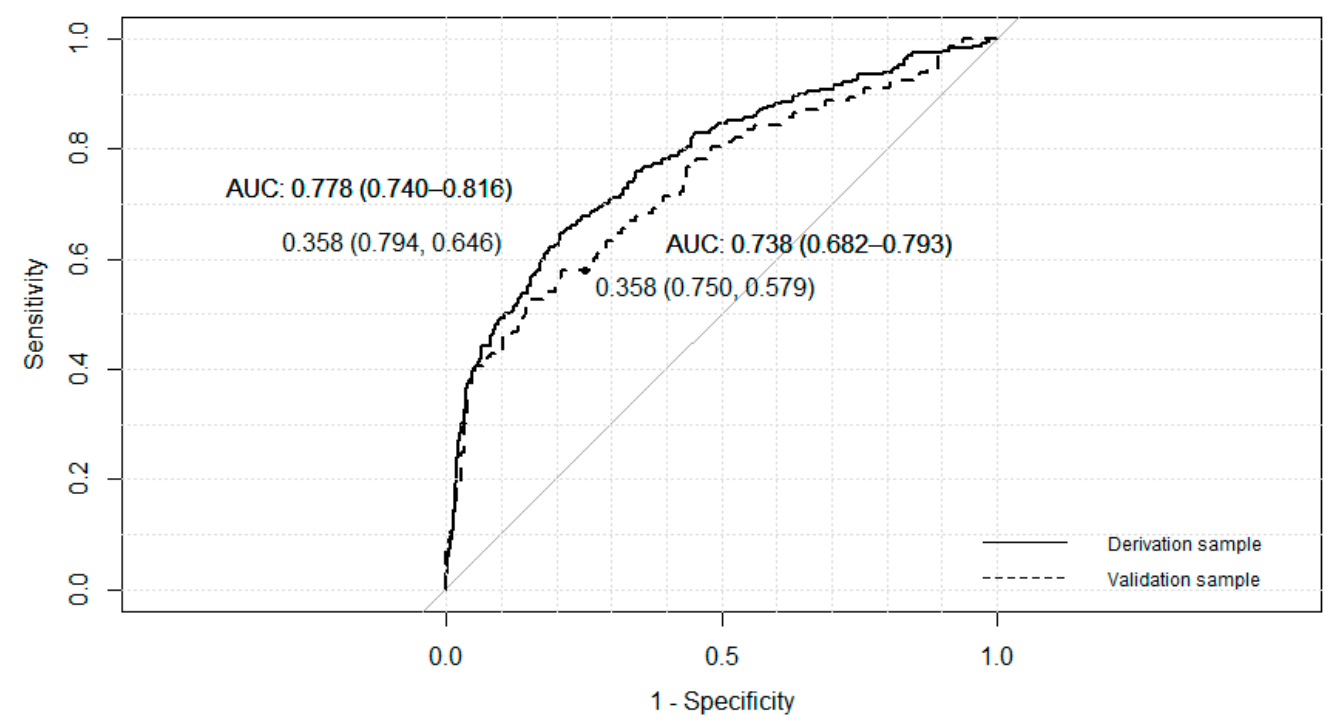

Figure 4. ROC curves for derivative and validation samples, model A, AUC = Area Under the Curve.

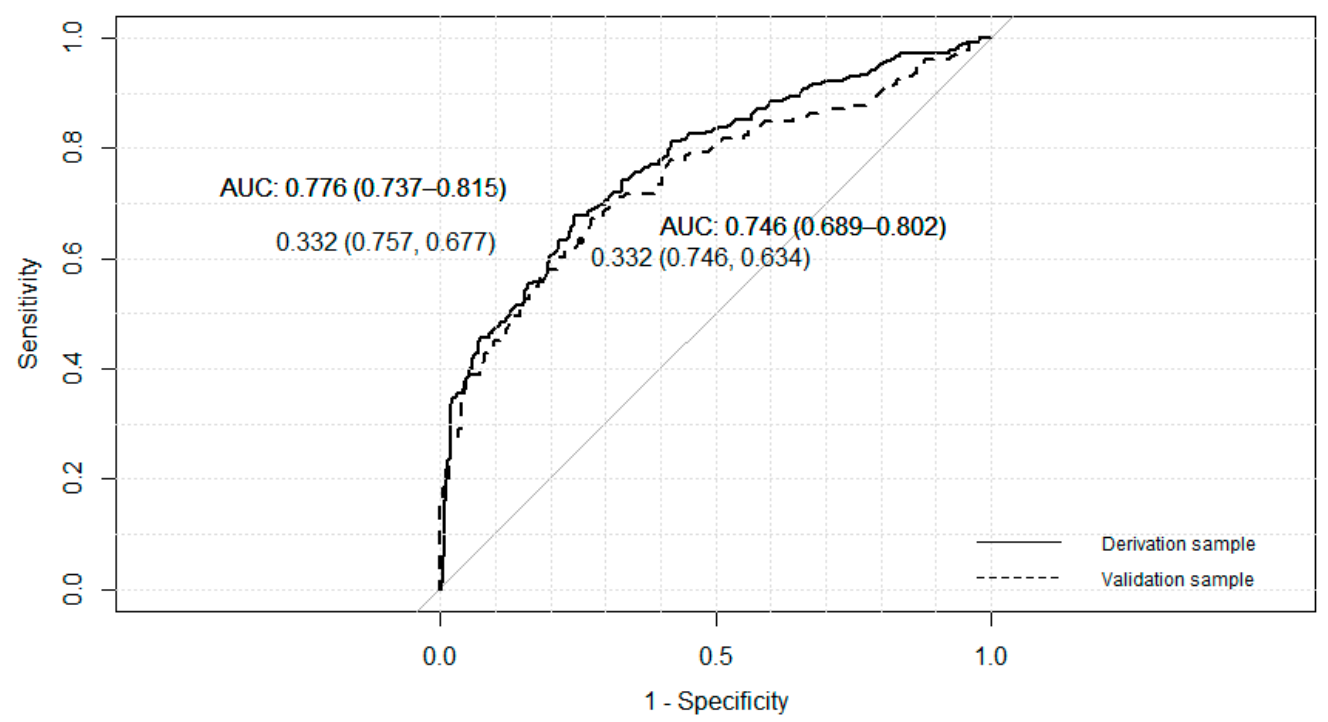

Figure 5. ROC curves for derivative and validation samples, model B, AUC = Area Under the Curve.

The final A model, adjusted with the derived sample, shows an area under the ROC curve of 0.778 (95\% CI: $0.74-0.82$ ). A cutoff point of 0.358 provided a sensitivity of $64.6 \%$ and a specificity of $79.4 \%$. This cutoff point allowed us to rank similar proportions of people in the validation sample, with an area under the curve of 0.738 (95\% CI: 0.68-0.79).

The B model, adjusted with the derived sample, shows an area under the ROC curve of 0.776 (95\% CI: 0.74-0.82). A cutoff point of 0.332 provided a sensitivity of $67.7 \%$ and a specificity of $75.7 \%$. This cutoff point allowed us to rank similar proportions of people in the validation sample, with an area under the curve of 0.746 (95\% CI: 0.69-0.80).

Model C, adjusted with the derived sample, shows an area under the ROC curve of 0.775 ( $95 \%$ CI: $0.74-0.82$ ). A cutoff point of 0.325 provided a sensitivity of $69.3 \%$ and a specificity of $74.2 \%$. This cutoff point allowed us to rank similar proportions of people in the validation sample, with an area under the curve of 0.744 (95\% CI: 0.69-0.80).

The analysis of the possible scenarios for each model is shown in the following figures, which show the scores an individual would have in the model according to his/her circumstances and whether he/she would exceed the threshold (horizontal line) to be classified as positive, i.e., gambling at $\mathrm{T}_{2}$. 
The $\mathrm{X}$-axis collects the values of risk perception $(0-4)$ and the points of the values of the fourth variable in each model.

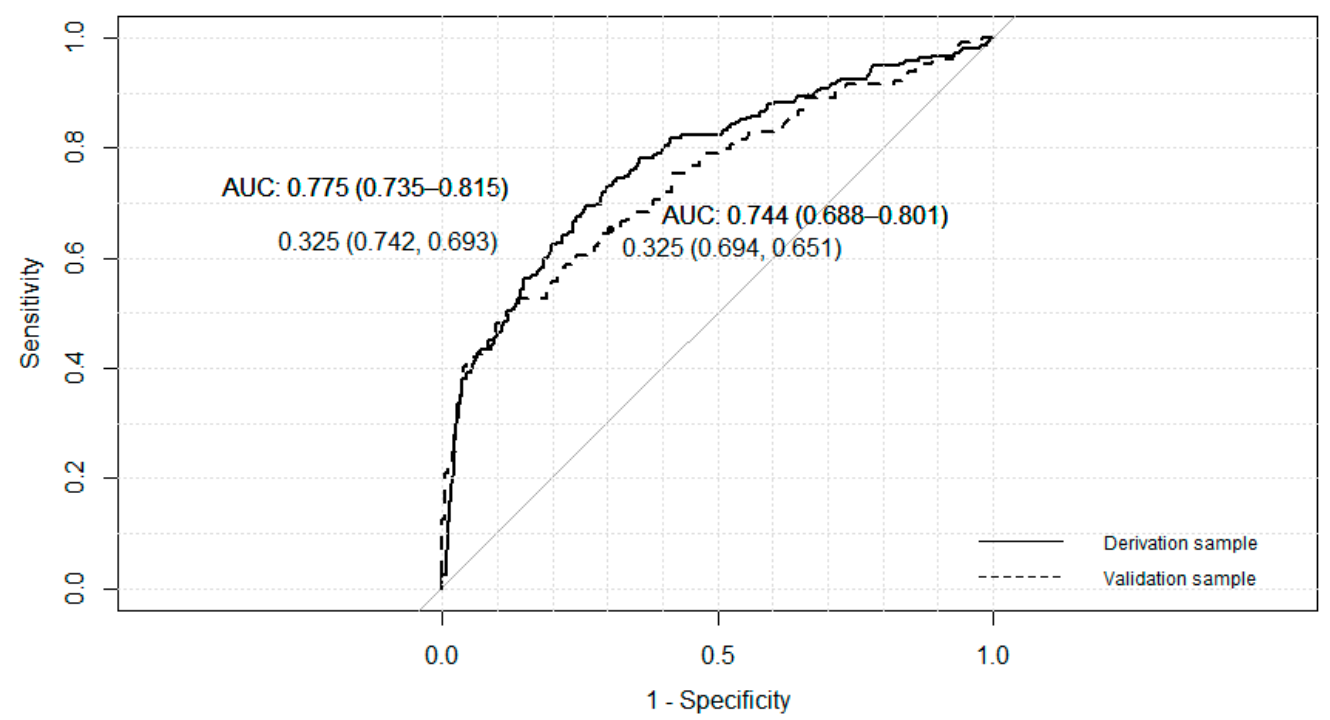

Figure 6. ROC curves for derivative and validation samples, model C, AUC = Area Under the Curve.

Figure 7 shows an analysis of the possible scenarios for model A. Thus, for example, a man who has played in $T_{1}$ would be classified as a gambler in $T_{2}$, regardless of his risk perception and sensation-seeking score; while a woman who has played in $\mathrm{T}_{1}$ may be classified as a non-gambler in $\mathrm{T}_{2}$ if her risk perception is high and her sensation-seeking score is low.
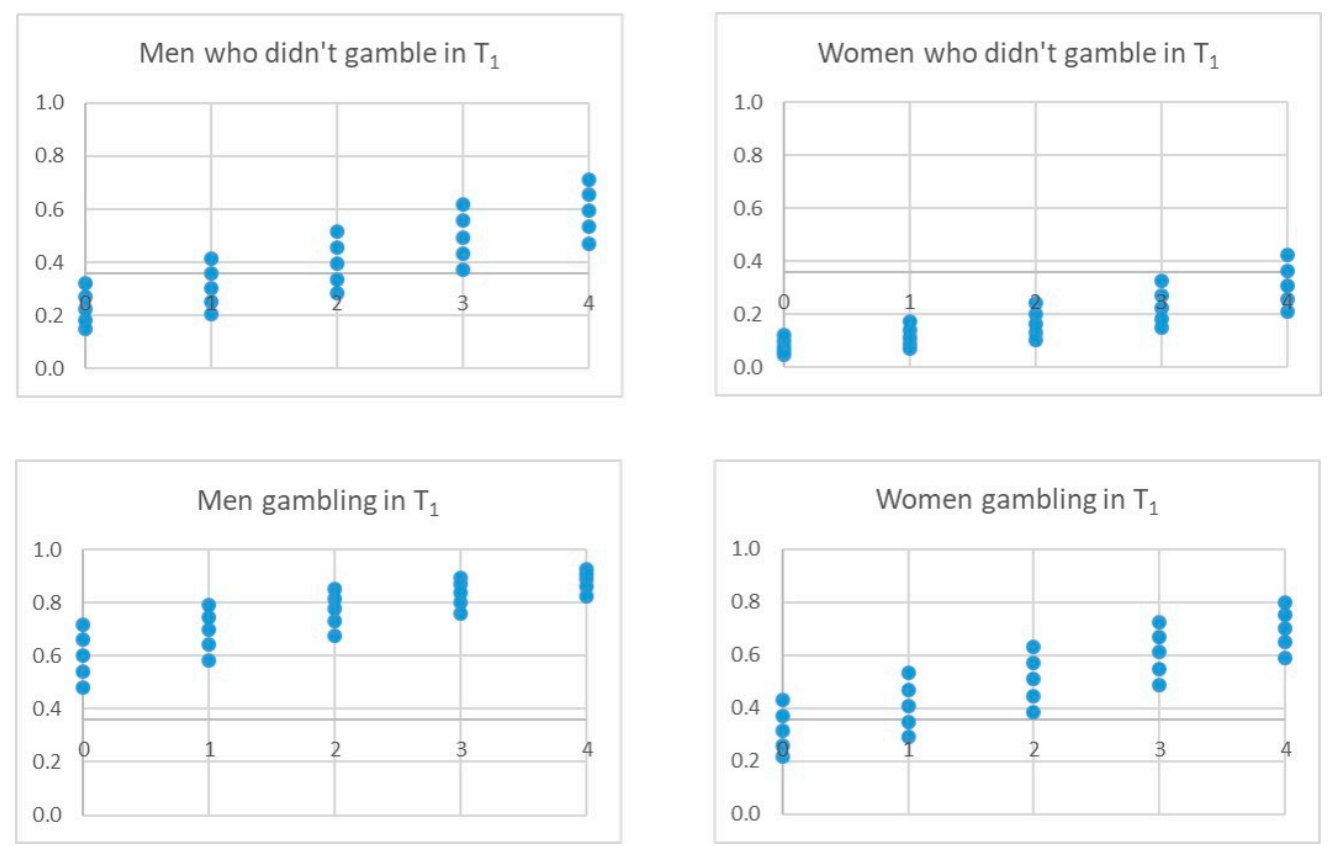

Figure 7. Possible scenarios for model A. Note. The X-axis represents the values of the variable risk perception $(0,4)$. The dots represent the score on the sensation-seeking variable. The horizontal line represents the threshold for a person to be classified as a gambler or not at $\mathrm{T}_{2}$.

Figure 8 shows the possible scenarios for model B. For example, the fact that friends gamble can be a determining factor in classifying boys as players in $T_{2}$, without having played in $T_{1}$, even with a perceived high risk. This occurs to a lesser extent in girls. 

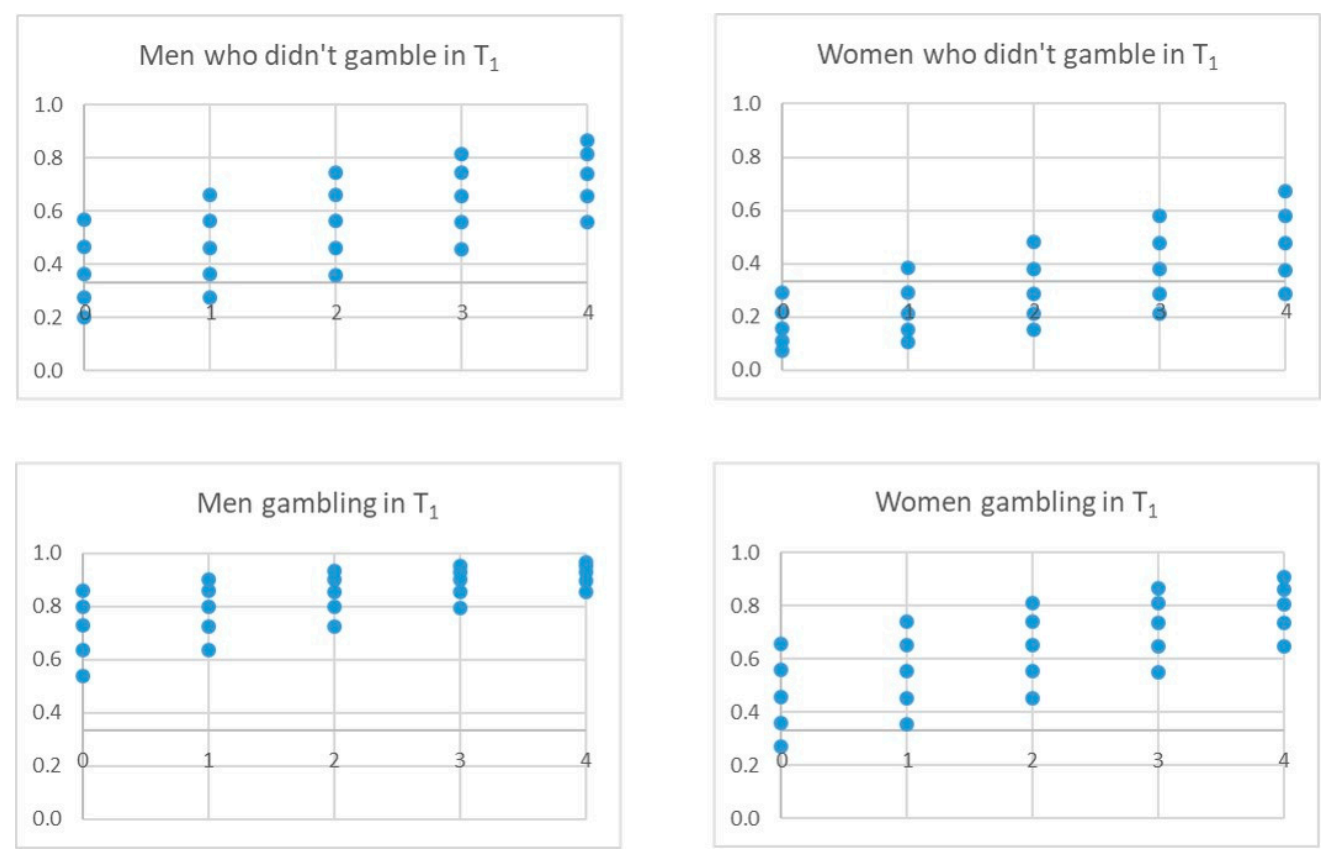

Figure 8. Possible scenarios for model B. Note The $\mathrm{X}$-axis represents the values of the variable risk perception $(0,4)$. The dots represent the score on the Peer pressure (friends) variable. The horizontal line represents the threshold for a person to be classified as a gambler or not at $T_{2}$.

Figure 9 represents the possible scenarios for model C. For example, the accessibility variable seems to have a greater effect on those who have not gambled in $\mathrm{T}_{1}$, both for girls and boys, and little effect on those who have already gambled in $\mathrm{T}_{1}$.
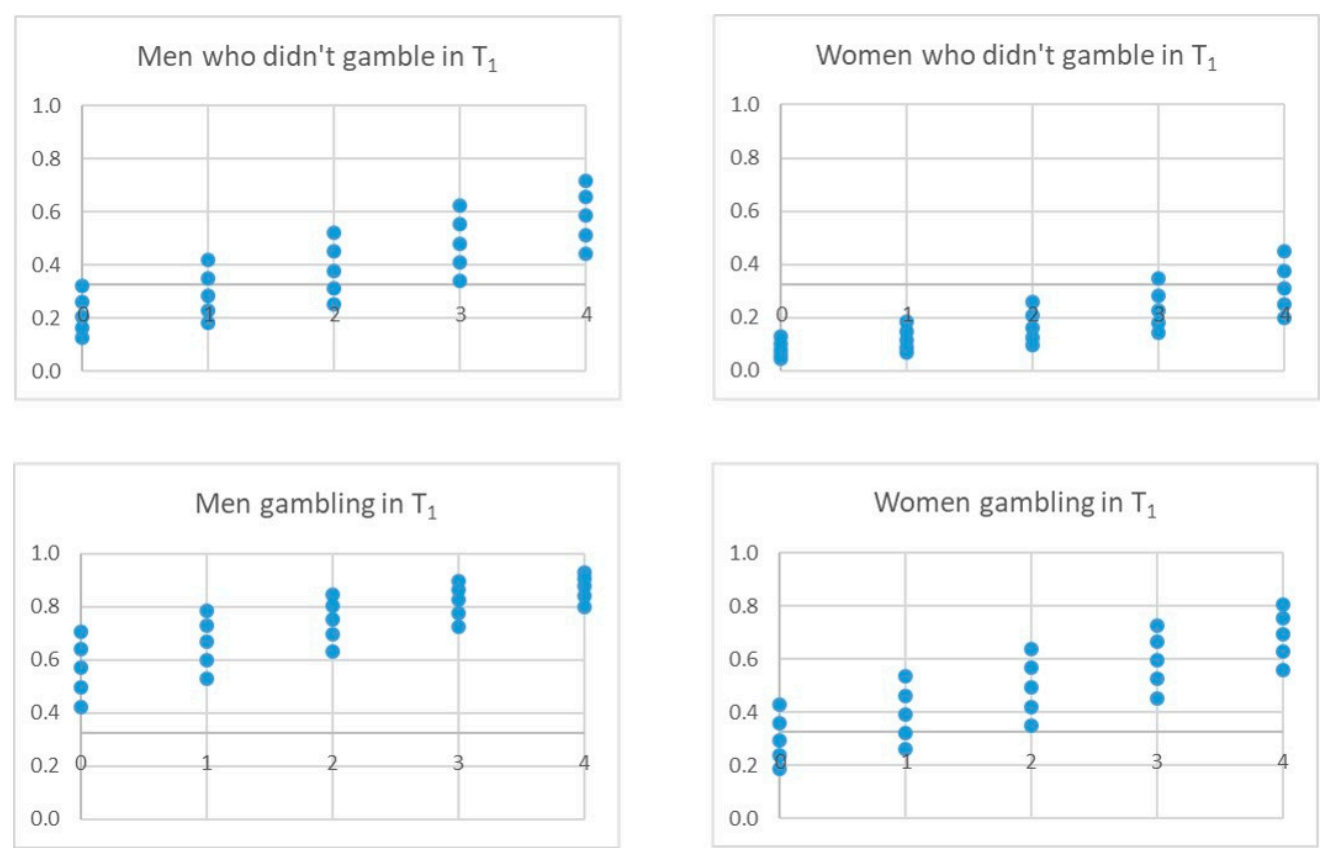

Figure 9. Possible scenarios for model C. Note The $\mathrm{X}$-axis represents the values of the variable risk perception $(0,4)$. The dots represent the score on the accessibility variable. The horizontal line represents the threshold for a person to be classified as a gambler or not at $\mathrm{T}_{2}$. 


\section{Discussion}

The objectives of this study were to determine the prevalence of gambling from a longitudinal perspective, to identify the psychosocial factors that are associated with the onset and maintenance of gambling behavior after one year $\left(\mathrm{T}_{2}\right)$, and to fit a mathematical model (multivariate logistic regression with a longitudinal approach) to predict gambling behavior from these psychosocial factors.

This work supposes a rational approach to the greater knowledge of the predictive factors that can act in the onset and maintenance of gambling in adolescents. Thus, it represents an advance in our country, as it is a pioneering study that combines from a longitudinal perspective different levels of individual and psychosocial risk factors, and includes factors typically considered as components of school-based preventive programs (i.e., risk perception, peer pressure, media pressure, etc.) [70,71].

Regarding the first objective, the gambling frequency rates at $\mathrm{T}_{1}$ are similar to those reported by the Survey ESTUDES 2018 [8], both for the total results and for the trends according to age and gender. At $T_{2}$, the average age of the sample increases by one year, and the percentage of young people who gamble with high frequency practically doubles. Between 13 and 14 years old, 45\% of young people who did not gamble in $\mathrm{T}_{1}$ start gambling. These results are consistent with those found in similar studies $[83,84]$ and invite to reflect on the appropriate age to carry out preventive interventions.

Our results show a stable increase in gambling in adolescents aged 13-17 years. These findings contrast with other longitudinal studies such as those carried out by Delfabbro, King and Griffiths [67], which indicate that gambling shows little stability in young people, perhaps because their age ranges are between 16 and 21 years, encompassing the transition to young adulthood. Other studies suggest that there is an increasing trend in gambling, the prevalence growing rapidly in adolescents to decline in young adulthood $[69,85]$.

Gambling presents a sexual dimorphism in high frequencies of gambling, where the male-female ratio is 5:1. This difference is reduced at $T_{2}$ when the average age is one-year-older, suggesting that girls who gamble at high frequencies do it later than boys. For low and moderate frequencies, the gender differences decrease, becoming statistically no-significant. The rates of risk gambling (4.76\%) or problem gambling (2.87\%) and the difference between boys and girls are in line with those found in other similar studies [2,4,17] and are higher than those found in studies of the adult population [12].

The univariate analyses of the predictive modeling of gambling behavior at $\mathrm{T}_{2}$ from the scores in the predictor variables at $\mathrm{T}_{1}$ exclude the variables "impulsivity" and "subjective norm" since they do not show statistically significant differences between the group "Does not gamble" and "Occasional Frequency" at $\mathrm{T}_{2}$. These results contradict the second hypothesis that predicts that all proposed factors will be associated with the initiation or maintenance of gambling behavior in the second year.

The analysis of the risk factors casts three models with similar predictive capacity. The models do not include interactions between variables to avoid complexity and difficulty of interpretation. The three models share three of the four predictive variables in $\mathrm{T}_{1}$ : gender, gambling behavior at $\mathrm{T}_{1}$ and risk perception. Hypothesis 3, which predicted gender and gambling behavior in the first year as predictive variables for gambling in the second year, is verified. As mentioned above, studies of gambling find a strong sexual dimorphism, so it was expected that being male would be one of the predictive variables of the models. Previous studies have found high rates of continuity with respect to the previous behavior, so it is plausible to think that gambling behavior in the previous year is a good predictor $[19,86]$. The third common variable is "Risk perception". The systematic review by Spurrier and Blaszczynski [60] indicates that the most problematic gamblers perceived the game to be less harmful than non-gamblers or problem gamblers. Therefore, increasing risk perception should be a goal of preventive interventions. Taking into account that risk perception becomes more resistant when the person has experienced the behavior, according to the results of our study, it would be desirable to carry out prevention programs between the ages of 13 or 14 years, before adolescents have their first gambling experiences.

In addition to the variables shared by the three models, model A included the variable "sensation-seeking", model B included "peer pressure," and model C "accessibility". All three 
are variables that appear as risk factors for adolescent gambling in various studies $[17,38,55,87-89]$. The commonality of the three models is shaped by a behavior variable: "frequency of gambling," a demographic variable: "gender", and a cognitive variable: "risk perception". The variable "sensation-seeking" characterizes the A model as a predictive model from the individual perspective. This result is in line with what was observed in recent longitudinal studies and systematic reviews $[19,90]$. The variable "peer pressure" characterizes model B as a predictive model from the immediate environment. Consistent with this result, other studies have previously shown that boys who gamble at a high-frequency often report the highest level of peer pressure [41]. Moreover, the variable "accessibility" characterizes model C as an environmental predictive model, named as "availability" in previous works; it has been identified as a risk factor, especially for online gambling [21].

The longitudinal design and sample size offer robustness to the study; however, a 12 months period between measures is a short period to examine the evolution of gambling habits over time. In general, the findings should be interpreted under the limitations of self-reporting and cohort studies, including possible biases and attrition of the participants between measures. In this sense, the loss of $40 \%$ of the sample in the follow-up invites to reflect on its impact on the results and its validity. Likewise, it would have been desirable to include minors not included in the regular educational system. Although they are a minority, their unique sociodemographic features would enrich the results. Finally, the disadvantages of the concentrated location of the sample must be taken into account and require caution in generalizing results.

The results of this study contribute to a better knowledge of the factors that predict the onset and maintenance of gambling in the adolescent population, reinforce the multidimensional definition of gambling behavior and the need to take into account individual, psychosocial and environmental factors in the design of preventive interventions [91-93].

The continuity rate is worrying, with $70 \%$ of adolescents who gamble continuing to do so a year later. These findings suggest that universal prevention programs should target children under the age of 15 to anticipate the age of onset. Regarding the factors commonly proposed as components of preventive interventions (i.e., risk perception, attitude change, the illusion of control, media pressure) [70,71], our study supports that prevention programs should target risk perception and resistance to peer pressure. In this sense, other studies in our country confirm low levels of risk perception and that the usual motivation among adolescents in the initial stages of gambling is to feel part of the peer group [94]. Moreover, the identification of individual variables such as sensation-seeking and the ability to resist peer pressure is a clear caveat for designing prevention programs. In addition, the perception of high accessibility must be understood as an alert for the need for community and environmental preventive approaches, with the participation of public administrations and civil society, in compliance with the rules and regulation of media pressure. In this sense, the results indicate the need to implement initiatives that favor compliance with current legislative measures. Gambling venue and website liability could be increased through the implementation of specific normative strategies and actions. Some of these measures are to implement more effective access control systems, also online. These rules and actions may apply to the establishment owner or staff. These types of actions have been effective in preventing alcohol abuse [95].

\section{Conclusions}

In conclusion, our study highlights the role of risk perception, sensation-seeking, peer pressure and accessibility as psychosocial variables predicting the onset and maintenance of play among adolescents. These variables should be taken into account as objectives in the design of preventive interventions. In terms of age of onset and high continuation rate, we suggest that universal prevention programmes should target children under 15 years of age to anticipate the age of onset. 
Author Contributions: Conceptualization, D.L.-I. and V.C.-P.; methodology, J.A.M.; software, J.V.S.-H.; formal analysis, J.V.S.-H.; data curation, V.C.-P.; writing—original draft preparation, Á.B.-G.; writing Á.B.-G.; Review and editing. J.A.M. and D.L.-I.; project administration and funding acquisition, D.L.-I. All authors have read and agreed to the published version of the manuscript.

Funding: This research was co-funded by the Provincial Council of Alicante through the project entitled "El juego de apuestas en adolescentes de la provincia de Alicante II. Estudio longitudinal de los hábitos de juego de apuestas y los predictores psicosociales".

Acknowledgments: J.V.S.-H. is partially supported by the Ministerio de Economía y Competitividad of Spain (grant no. MTM2017-83850-P).

Conflicts of Interest: The authors declare no conflict of interest.

\section{References}

1. Andrie, E.K.; Tzavara, C.K.; Tzavela, E.; Richardson, C.; Greydanus, D.; Tsolia, M.; Tsitsika, A.K. Gambling involvement and problem gambling correlates among European adolescents: Results from the European Network for Addictive Behavior study. Soc. Psychiatry Psychiatr. Epidemiol. 2019, 54, 1429-1441. [CrossRef]

2. ESPAD Group. ESPAD Report 2019: Results from the European School Survey Project on Alcohol and Other Drugs; Publications Office of the European Union: Luxembourg, 2020.

3. Kristiansen, S.G.; Jensen, S.M. Prevalence and correlates of problematic gambling among Danish adolescents. Int. J. Soc. Welf. 2014, 23, 89-99. [CrossRef]

4. Chóliz, M.; Lamas, J. Place your bets, children! The frequency of gambling among minors and their relationship with gambling addiction indicators. Rev. Esp. Drogodepend. 2017, 42, 34-37.

5. Caselles, P.; Cabrera, V.; Lloret, D. Prevalencia del juego de apuestas en adolescentes. Un análisis de los factores asociados. Health Addict. 2018, 18, 165-173. [CrossRef]

6. Observatorio Español de las Drogas y las Adicciones. Informe Sobre Adicciones Comportamentales. Madrid; 2019. Available online: http://www.pnsd.mscbs.gob.es (accessed on 26 August 2019).

7. ESPAD Group. Results from the European School Survey Project on Alcohol and Other Drugs; ESPAD Report 2015; Publications Office of the European Union: Luxembourg, 2016.

8. Observatorio Español Sobre Adicciones. ESTUDES 2018/19. 2019. Available online: https://pnsd.sanidad.gob. es/fr/profesionales/sistemasInformacion/sistemaInformacion/pdf/ESTUDES_2018-19_Informe.pdf (accessed on 23 July 2020).

9. McCormack, A.; Shorter, G.W.; Griffiths, M.D. Characteristics and Predictors of Problem Gambling on the Internet. Int. J. Mental Health Add. 2013, 11, 634-657. [CrossRef]

10. Newall, P.W.S. Dark nudges in gambling. Add. Res. Theory 2019, 27, 65-67. [CrossRef]

11. Chóliz, M.; Marcos, M.; Lázaro-Mateo, J. The Risk of Online Gambling: A Study of Gambling Disorder Prevalence Rates in Spain. Int J Ment Health Addict. 2019. [CrossRef]

12. Dirección General de Ordenación del Juego. Estudio Sobre la Prevalencia, Comportamiento y Características de los Usuarios de Juegos de Azar en España 2015; Ministerio de Hacienda y Administraciones Públicas: Madrid, Spain, 2015.

13. Canale, N.; Griffiths, M.D.; Vieno, A.; Siciliano, V.; Molinaro, S. Impact of Internet gambling on problem gambling among adolescents in Italy: Findings from a large-scale nationally representative survey. Comput. Hum. Behav. 2016, 57, 99-106. [CrossRef]

14. Griffiths, M. Internet Gambling: Issues, Concerns, and Recommendations. Cyberpsychol. Behav. 2003, 6, 557-568. [CrossRef]

15. Shaffer, H.J.; Shaffer, P.M. Psychiatric epidemiology, nosology, and treatment: Considering internet gambling. Psychiatr. Annals. 2014, 44, 371-378. [CrossRef]

16. Calado, F.; Alexandre, J.; Rosenfeld, L.; Pereira, R.; Griffiths, M.D. The Efficacy of a Gambling Prevention Program among High-School Students. J. Gamb. Stud. 2020, 36, 573-595. [CrossRef] [PubMed]

17. González-Roz, A.; Fernández-Hermida, J.R.; Weidberg, S.; Martínez-Loredo, V.; Secades-Villa, R. Prevalence of Problem Gambling Among Adolescents: A Comparison Across Modes of Access, Gambling Activities, and Levels of Severity. J. Gamb. Stud. 2016, 33, 371-382. [CrossRef] [PubMed]

18. Calado, F.; Griffiths, M.D. Problem gambling worldwide: An update and systematic review of empirical research (2000-2015). J. Behav. Add. 2016, 5, 592-613. [CrossRef] [PubMed] 
19. Dowling, N.A.; Merkouris, S.S.; Greenwood, C.J.; Oldenhof, E.; Toumbourou, J.W.; Youssef, G.J. Early risk and protective factors for problem gambling: A systematic review and meta-analysis of longitudinal studies. Clin. Psychol. Rev. 2017, 51, 109-124. [CrossRef] [PubMed]

20. Floros, G.D. Gambling disorder in adolescents: Prevalence, new developments and treatment challenges. Adolesc. Health Med. Ther. 2018, 9, 43-51. [CrossRef] [PubMed]

21. Calado, F.; Alexandre, J.; Griffiths, M.D. Prevalence of Adolescent Problem Gambling: A Systematic Review of Recent Research. J. Gamb. Stud. 2017, 33, 397-424. [CrossRef] [PubMed]

22. El-Guebaly, N.; Casey, D.M.; Currie, S.R.; Hodgins, D.C.; Schopflocher, D.P.; Smith, G.J.; Williams, R.J. The Leisure, Lifestyle, \& Lifecycle Project (LLLP): A Longitudinal Study of Gambling in Alberta; Final Report for the Alberta Gambling Research Institute; Alberta Gambling Research Institute: Banff, AB, Canada, 2015.

23. Williams, R.J.; Hann, R.G.; Schopflocher, D.P.; West, B.L.; McLaughlin, P.; White, N.; King, K.; Flexhaug, T. Quinte Longitudinal Study of Gambling and Problem Gambling. Ontario. 2015. Available online: http://hdl.handle.net/10133/3641 (accessed on 29 February 2020).

24. Dussault, F.; Dufour, M.; Brunelle, N.; Tremblay, J.; Rousseau, M.; Leclerc, D.; Cousineau, M.M.; Berbiche, D. Consistency of Adolescents' Self-Report of Gambling Age of Onset: A Longitudinal Study. J. Gamb. Stud. 2019, 35, 533-544. [CrossRef]

25. Chóliz, M. The Challenge of Online Gambling: The Effect of Legalization on the Increase in Online Gambling Addiction. J. Gamb. Stud. 2016, 32, 749-756. [CrossRef]

26. Dickson, L.M.; Derevensky, J.L.; Gupta, R. The prevention of gambling problems in youth: A conceptual framework. J. Gamb. Stud. 2002, 18, 97-159. [CrossRef]

27. Dickson-Gillespie, L.; Rugle, L.; Rosenthal, R.; Fong, T. Preventing the incidence and harm of gambling problems. J. Prim. Prev. 2008, 29, 37-55. [CrossRef]

28. Huic, A.; Kranzelic, V.; Dodig Hundric, D.; Ricijas, N. Who Really Wins? Efficacy of a Croatian Youth Gambling Prevention Program. J. Gamb. Stud. 2017, 33, 1011-1033. [CrossRef] [PubMed]

29. Derevensky, J.L. Youth Gambling: Some Current Misconceptions. Austin J. Psychiatr. Behav. Sci. 2015, 2, 1-9.

30. Derevensky, J.L.; Gilbeau, L. Preventing adolescent gambling problems. In Gambling Disorder; Springer International Publishing: Cham, Switzerland, 2019; pp. 297-311.

31. St-Pierre, R.; Derevensky, J.L. Youth Gambling Behavior: Novel Approaches to Prevention and Intervention; Current Addiction Reports; Springer: Cham, Switzerland, 2016; Volume 3, pp. 157-165.

32. Oh, B.C.; Ong, Y.J.; Loo, J.M.Y. A review of educational-based gambling prevention programs for adolescents. Asian J. Gamb. Issues Public Health 2017, 7, 4. [CrossRef] [PubMed]

33. Hill, K.M.; Pilling, M.; Foxcroft, D.R. Alcohol-related affordances and group subjectivities: A Q-Methodology study. Drugs Educ. Prev. Policy 2018, 25, 376-385. [CrossRef]

34. Burkhart, G. Confiamos demasiado en el valor de la cognición y de la educación en la prevención? Rev. Esp. Drogodepend. 2015, 40, 61-70.

35. UNODC. International Standards on Drug Use Prevention Second Updated Edition; UNODC and WHO: Vienna, Austria, 2018.

36. Harden, K.P.; Tucker-Drob, E.M. Individual differences in the development of sensation seeking and impulsivity during adolescence: Further evidence for a dual systems model. Dev. Psychol. 2011, 47, 739-746. [CrossRef]

37. Romer, D. Adolescent risk taking, impulsivity, and brain development: Implications for prevention. Dev. Psychobiol. 2010, 52, 263-276. [CrossRef]

38. Cosenza, M.; Nigro, G. Wagering the future: Cognitive distortions, impulsivity, delay discounting, and time perspective in adolescent gambling. J. Adolesc. 2015, 45, 56-66. [CrossRef]

39. Donati, M.A.; Chiesi, F.; Iozzi, A.; Manfredi, A.; Fagni, F.; Primi, C. Gambling-Related Distortions and Problem Gambling in Adolescents: A Model to Explain Mechanisms and Develop Interventions. Front. Psychol. 2018, 8, 2243. [CrossRef]

40. Secades-Villa, R.; Martínez-Loredo, V.; Grande-Gosende, A.; Fernández-Hermida, J.R. The Relationship between Impulsivity and Problem Gambling in Adolescence. Front. Psychol. 2016, 7, 1931. [CrossRef]

41. Donati, M.A.; Chiesi, F.; Primi, C. A model to explain at-risk/problem gambling among male and female adolescents: Gender similarities and differences. J. Adolesc. 2013, 36, 129-137. [CrossRef] [PubMed] 
42. Shenassa, E.D.; Paradis, A.D.; Dolan, S.L.; Wilhelm, C.S.; Buka, S.L. Childhood impulsive behavior and problem gambling by adulthood: A 30-year prospective community-based study. Addiction 2012, 107, 160-168. [CrossRef] [PubMed]

43. Derevensky, J.L.; Gilbeau, L. Adolescent Gambling: Twenty-five Years of Research. Can. J. Add. 2015, 6, 37-45.

44. Li, S.; Zhou, K.; Sun, Y.; Rao, L.-L.; Zheng, R.; Liang, Z.-Y. Anticipated Regret, Risk Perception, or Both: Which is Most Likely Responsible for Our Intention to Gamble? J. Gamb. Stud. 2010, 26, 105-116. [CrossRef] [PubMed]

45. Canale, N.; Vieno, A.; ter Bogt, T.; Pastore, M.; Siciliano, V.; Molinaro, S. Adolescent Gambling-Oriented Attitudes Mediate the Relationship between Perceived Parental Knowledge and Adolescent Gambling: Implications for Prevention. Prev. Sci. 2016, 17, 970-980. [CrossRef] [PubMed]

46. León-Jariego, J.C.; Parrado-González, A.; Ojea-Rodríguez, F.J. Behavioral Intention to Gamble among Adolescents: Differences between Gamblers and Non-gamblers-Prevention Recommendations. J. Gamb. Stud. 2019, 36, 1-18. [CrossRef]

47. West, R.; Michie, S. A brief introduction to the COM-B Model of behaviour and the PRIME Theory of motivation. Qeios 2020. [CrossRef]

48. Fishbein, M.; Ajzen, I. Predicting and Changing Behavior: The Reasoned Action Approach; Psychology Press (Taylor \& Francis): New York, NY, USA, 2010.

49. Dixon, R.W.; Youssef, G.J.; Hasking, P.; Yücel, M.; Jackson, A.C.; Dowling, N.A. The relationship between gambling attitudes, involvement, and problems in adolescence: Examining the moderating role of coping strategies and parenting styles. Addict. Behav. 2016, 58, 42-46. Available online: https://www.sciencedirect. com/science/article/abs/pii/S0306460316300363 (accessed on 30 September 2019). [CrossRef]

50. Schneider, L.A.; King, D.L.; Delfabbro, P.H. Family factors in adolescent problematic Internet gaming: A systematic review. J. Behav. Add. 2017, 6, 321-333. [CrossRef]

51. Allami, Y.; Vitaro, F.; Brendgen, M.; Carbonneau, R.; Tremblay, R.E. Identifying at-risk profiles and protective factors for problem gambling: A longitudinal study across adolescence and early adulthood. Psychol. Add. Behav. 2018, 32, 373-382. [CrossRef]

52. Frisone, F.; Settineri, S.; Sicari, F.; Merlo, E.M. Gambling in adolescence: A narrative review of the last 20 years. J. Add. Dis. 2020, 38, 1-20. [CrossRef] [PubMed]

53. Russell, A.; Langham, E.; Hing, N. Social influences normalize gambling-related harm among higher risk gamblers. J. Behav. Add. 2018, 4, 1100-1111. [CrossRef] [PubMed]

54. Hing, N.; Cherney, L.; Blaszczynski, A.; Gainsbury, S.M.; Lubman, D.I. International Gambling Studies Do advertising and promotions for online gambling increase gambling consumption? An exploratory study. Int. Gamb. Stud. 2014, 14, 394-409. [CrossRef]

55. Lloret, D.; Perona, V.; Castaños, A.; Segura-Heras, J.V.; Antón-Esclápez, M.A.; Caselles, P. Estudio Longitudinal del Juego de Apuestas Entre Adolescentes y Sus Factores de Riesgo. Alicante 2016-2017; Diputación Provincial de Alicante: Alicante, Spain, 2018.

56. Pitt, H.; Thomas, S.L.; Bestman, A.; Randle, M.; Daube, M. Do betting advertisements contain attention strategies that may appeal to children? An interpretative content analysis. Health Promot. J. Aust. 2018, 29, 265-273. [CrossRef] [PubMed]

57. Nyemcsok, C.; Thomas, S.L.; Bestman, A.; Pitt, H.; Daube, M.; Cassidy, R. Young people's recall and perceptions of gambling advertising and intentions to gamble on sport. J. Behav. Add. 2018, 7, 1068-1078. [CrossRef] [PubMed]

58. King, D.; Delfabbro, P.; Griffiths, M. The Convergence of Gambling and Digital Media: Implications for Gambling in Young People. J. Gamb. Stud. 2010, 26, 175-187. [CrossRef] [PubMed]

59. Ricijas, N.; Dodig Hundric, D.; Huic, A. Predictors of adverse gambling related consequences among adolescent boys. Child. Youth Serv. Rev. 2016, 67, 168-176. [CrossRef]

60. Spurrier, M.; Blaszczynski, A. Risk Perception in Gambling: A Systematic Review. J. Gamb. Stud. 2014, 30, 253-276. [CrossRef]

61. Scholes-Balog, K.E.; Hemphill, S.A.; Toumbourou, J.W.; Dowling, N.A. Problem gambling and internalising symptoms: A longitudinal analysis of common and specific social environmental protective factors. Add. Behav. 2015, 46, 86-93. [CrossRef] 
62. Smith, M.; Chambers, T.; Abbott, M.; Signal, L. High Stakes: Children's Exposure to Gambling and Gambling Marketing Using Wearable Cameras. Int. J. Ment. Health Add. 2019. [CrossRef]

63. Hayer, T.; Kalke, J.; Meyer, G.; Brosowski, T. Do simulated gambling activities predict gambling with real money during adolescence? Empirical findings from a longitudinal study. J. Gamb. Stud. 2018, 34, 929-947. [CrossRef] [PubMed]

64. Dussault, F.; Brunelle, N.; Kairouz, S.; Rousseau, M.; Leclerc, D.; Tremblay, J.; Cousineau, M.M.; Dufour, M. Transition from playing with simulated gambling games to gambling with real money: A longitudinal study in adolescence. Int. Gamb. Stud. 2017, 17, 386-400. [CrossRef]

65. Li, W.; Mills, D.; Nower, L. The relationship of loot box purchases to problem video gaming and problem gambling. Add. Behav. 2019, 97, 27-34. [CrossRef] [PubMed]

66. Dahlberg, L.L.; Krug, E.G. Violence: A global public health problem. In World Report on Violence and Health; Krug, E.G., Dahlberg, L.L., Mercy, J.A., Zwi, A.B., Lozano, R., Eds.; World Health Organization: Geneva, Switzerland, 2002; pp. 1-56.

67. Delfabbro, P.; King, D.; Griffiths, M.D. From adolescent to adult gambling: An analysis of longitudinal gambling patterns in South Australia. J. Gamb. Stud. 2014, 30, 547-563. [CrossRef]

68. Dussault, F.; Brendgen, M.; Vitaro, F.; Wanner, B.; Tremblay, R.E. Longitudinal links between impulsivity, gambling problems and depressive symptoms: A transactional model from adolescence to early adulthood. J. Child Psychol. Psychiatr. 2011, 52, 130-138. [CrossRef]

69. Edgerton, J.; Melnyk, T.; Roberts, L. Problem Gambling and the Youth-to-Adulthood Transition: Assessing Problem Gambling Severity Trajectories in a Sample of Young Adults. J. Gamb. Stud. 2015, 31, 1463-1485. [CrossRef]

70. Keen, B.; Blaszczynski, A.; Anjoul, F. Systematic Review of Empirically Evaluated School-Based Gambling Education Programs. J. Gamb. Stud. 2017, 33, 301-325. [CrossRef]

71. Ladouceur, R.; Goulet, A.; Vitaro, F. Prevention programmes for youth gambling: A review of the empirical evidence. Int. Gamb. Stud. 2013, 13, 141-159. [CrossRef]

72. Vegni, N.; Melchiori, F.M.; D'Ardia, C.; Prestano, C.; Canu, M.; Piergiovanni, G.; Di Filippo, G. Gambling Behavior and Risk Factors in Preadolescent Students: A Cross Sectional Study. Front. Psychol. 2019, 10, 1287. [CrossRef]

73. Singer, J.D.; Willett, J.B. Applied Longitudinal Data Analysis: Modeling Change and Event Occurrence; Oxford University Press: Oxford, UK, 2003.

74. Winters, K.C.; Stinchfield, R.D.; Fulkerson, J. Toward the development of an adolescent gambling problem severity scale. J. Gamb. Stud. 1993, 9, 63-84. [CrossRef]

75. Becoña, E. Pathological gambling in Spanish children and adolescents: An emerging problem. Psychol. Rep. 1997, 81, 275-287. [CrossRef] [PubMed]

76. Plutchik, R.; van Praag, H. The measurement of suicidality, aggressivity and impulsivity. Prog. Neuro-Psychopharmacol. Biol. Psychiatr. 1989, 13, S23-S34. [CrossRef]

77. Rubio, G.; Montero, I.; Jáuregui, J.; Martínez, M.L.; Álvarez, S.; Marín, J.J. Validación de la Escala de Impulsividad de Plutchik en población española. Arch. Neurobiol. 1999, 61, 223-232.

78. Zuckerman, M. Dimensions of sensation seeking. J. Consult. Clin. Psychol. 1971, 36, 45. [CrossRef]

79. Hoyle, R.H.; Stephenson, M.T.; Palmgreen, P.; Lorch, E.P.; Donohew, R.L. Reliability and validity of a brief measure of sensation seeking. Personal. Individ. Differ. 2002, 32, 401-414. [CrossRef]

80. Palacios, J.R. Propiedades psicométricas del inventario de búsqueda de sensaciones para adolescentes en México (IBS-Mx). Int. J. Psychol. Res. 2015, 8, 46-60. [CrossRef]

81. Lloret, D.; Cabrera, V.; Núñez, R. Diseño y validación de la escala EDGAR-A (Early Detection of Gambling Abuse Risk-Adolescents). In IV International Congress of Clinical and Health Psychology on Children and Adolescents; Ediciones Pirámide: Madrid, Spain, 2018.

82. R Core Team. R: A Language and Environment for Statistical Computing; R Foundation for Statistical Computing: Vienna, Austria, 2019.

83. García Ruiz, P.; Buil, P.; Solé Moratilla, M.J. Consumos de riesgo: Menores y juegos de azar online. El problema del "juego responsable". Política Soc. 2016, 53, 551-575. [CrossRef] 
84. Kong, G.; Tsai, J.; Pilver, C.E.; Tan, H.S.; Hoff, R.A.; Cavallo, D.A.; Krishnan-Sarin, S.; Steinberg, M.A.; Rugle, L.; Potenza, M.N. Differences in gambling problem severity and gambling and health/functioning characteristics among Asian-American and Caucasian high-school students. Psychiatry Res. 2013, 210, 1071-1078. [CrossRef]

85. Barnes, G.M.; Welte, J.W.; Hoffman, J.H.; Tidwell, M.C. The Co-occurrence of Gambling with Substance Use and Conduct Disorder among Youth in the United States. Am. J. Add. 2011, 20, 166-173. [CrossRef]

86. Howe, P.D.L.; Vargas-Sáenz, A.; Hulbert, C.A.; Boldero, J.M. Predictors of gambling and problem gambling in Victoria, Australia. PLoS ONE 2019, 14, e0209277. [CrossRef]

87. Hing, N.; Russell, A.; Tolchard, B.; Nower, L. Risk factors for gambling problems: An analysis by gender. J. Gamb. Stud. 2016, 32, 511-534. [CrossRef] [PubMed]

88. Leeman, R.F.; Patock-Peckham, J.A.; Hoff, R.A.; Krishnan-Sarin, S.; Steinberg, M.A.; Rugle, L.J.; Potenza, M.N. Perceived parental permissiveness toward gambling and risky behaviors in adolescents. J. Behav. Add. 2014, 3, 115-123. [CrossRef] [PubMed]

89. Situ, J.; Mo, Z. Risk Propensity, Gambling Cognition and Gambling Behavior: The Role of Family and Peer Influences. J. Educ. Dev. Psychol. 2016, 6, 77-94. [CrossRef]

90. Pisarska, A.; Ostaszewski, K. Factors associated with youth gambling: Longitudinal study among high school students. Public Health 2020, 184, 33-40. [CrossRef] [PubMed]

91. Griffiths, M. A “components" model of addiction within a biopsychosocial framework. J. Subst. Use 2005, 10, 191-197. [CrossRef]

92. Pitt, H.; Thomas, S.L.; Bestman, A.; Stoneham, M.; Daube, M. “It's just everywhere!" Children and parents discuss the marketing of sports wagering in Australia. Aust. N. Z. J. Public Health 2016, 40, 480-486. [CrossRef] [PubMed]

93. Sapthiang, S.; van Gordon, W.; Shonin, E.; Griffiths, M.D. Adolescent problem gambling requires community-level health promotion approaches. Add. Res. Theory 2019, 28, 91-94. [CrossRef]

94. Chóliz, M.; Marcos, M. Adicción al Juego en la Juventud de la Comunitat Valenciana; Consell Valencià de la Joventut: Valencia, Spain, 2020.

95. Wagenaar, A.C.; Holder, H.D. Effects of Alcoholic Beverage Server Liability on Traffic Crash Injuries. Alcohol. Clin. Exp. Res. 1991, 15, 942-947. [CrossRef]

Publisher's Note: MDPI stays neutral with regard to jurisdictional claims in published maps and institutional affiliations.

(C) 2020 by the authors. Licensee MDPI, Basel, Switzerland. This article is an open access article distributed under the terms and conditions of the Creative Commons Attribution (CC BY) license (http://creativecommons.org/licenses/by/4.0/). 